\title{
The Impact of Bilingualism on the Creative Capabilities of Kindergarten Children in Riyadh, Saudi Arabia
}

\author{
Al Johara Fahad Al Saud ${ }^{1}$ \\ ${ }^{1}$ Education Policies and Kindergarten Section, College of Education, King Saud University, Saudi Arabia \\ Correspondence: Al Johara Fahad Al Saud, Educational Policies Department, Education Policies and \\ Kindergarten Section, College of Education, King Saud University, Prince Turkey street, Exit 2, Riyadh, Saudi \\ Arabia. Tel: 966-559-660-022. E-mail: aljoharaalsud@gmail.com
}

$\begin{array}{lc}\text { Received: April 9, 2016 } & \text { Accepted: May 13, } 2016 \quad \text { Online Published: September 28, } 2016 \\ \text { doi:10.5539/ies.v9n10p263 } & \text { URL: http://dx.doi.org/10.5539/ies.v9n10p263 }\end{array}$

This is a research project that was supported by a grant from the Research Center for the Humanities, Deanship of Scientific Research at King Saud University, 2016.

\begin{abstract}
Saudi Arabia is one of the countries that encounter the issue of bilingualism due to the spread of private schools that offer programs in different languages. This research is an attempt to investigate the impact of bilingualism on the creative capabilities (Fluency, Flexibility, Originality, Details) of kindergarten children in Riyadh. It aims at identifying the differences in the creative competences among children (monolingual and bilingual) in Saudi Arabia. To achieve the goals of the study, the researcher used the experimental method, as it is convenient to the nature of the study. She used the scale of Torrance of creative capacity in order to identify the creative abilities of children. The sample was randomly chosen and divided into two groups: the bilingual group $(\mathrm{n}=40)$, and the control monolingual group $(n=40)$. Results showed that there were statistically significant differences at $(\alpha=$ 0.05) between the mean scores of monolingual kindergarten children and the mean scores of bilingual kindergarten children in some creative capabilities in favor of monolingual children of the study. In light of the findings, the researcher recommended the need of resolving the controversy over the issue concerning when children can start to learn a foreign language.
\end{abstract}

Keywords: bilingualism, creative, competencies, children, Saudi Arabia

\section{Introduction}

The early childhood is considered as one of the most important stages in our lives. It is the stage that is marked by flexibility and willingness to learning and growing different skills and abilities. It is the stage of preparation, forming and building the milestone in the future children's development. Besides, at this stage children tend to guess, explore and experiment. This stage is not only essential in a child's life to start with a long series of changes, but also it is the most important stage in human life that influences the following stages. Therefore, it is necessary to take into consideration this important stage in human life (Al-Kilabi \& Tayeh, 2013).

The first five years of life are of great importance for children to acquire knowledge, which is reflected on their lives in the future (Abu Jado, 2004). Children can acquire any language at an early stage with a high degree of perfection. Acquisition is the ideal approach to create a great linguistic memory and use it in complete accuracy whenever the need arises. The child is required to be in a nurturing linguistic environment that enables him/her acquire the language gradually from his/her mother because she is the first person who is emotionally related to and listen to her voice and expressions during childhood. The term "Mother tongue" derived its power and importance from the outstanding role played by mothers in making the language closer to children. Child also can develop a linguistic mental ability from the members of the family (i.e., father, brothers and sisters). This process is twofold at the same time that is it is not only a formation of simple linguistic knowledge, but also it is the use of this knowledge at the same time to connect directly with the surrounding people (e.g., parents and relatives). Next, comes the role of friends and then the school followed by heading for other effects of audio-visual tools and so forth until the outcome of the way of speech becomes a natural result of accumulation of linguistic experiences that have had since childhood. 


\subsection{Statement of Problem}

Bilingualism implies the child's ability to deal with two languages by which it becomes easy for the child to select vocabulary of each language for the right situation. In this context, what is true for the acquisition of one language is true for acquiring more than one language if the society is bilingual or more, provided that the child is exposed to the same amount of linguistic experience for each language used in that community. However, if there appears any big difference between two languages, or more, in the acquisition, the result will be the control or dominance of a particular language (language of child's mental dictionary) on another language or other languages that make it equivalent or a subsidiary.

The opinions about children's ability to learn a second language and the appropriate method for not having coincidence between the two languages are different. Therefore, the present research is an attempt to investigate the effect of bilingualism at the pre-school stage on the growth of creativity. This study is especially significant as the Kingdom of Saudi Arabia is one of the countries that encounter the issue of bilingualism due to the spread of private schools that offer programs in different languages. Further, up to the researcher's knowledge, there are only few studies that addressed the effect of bilingualism on the cognitive development, such as (Metwally, 2009). However, no studies have been conducted on the bilingualism's effect on creativity of kindergarten children in Saudi Arabia.

\subsection{Research Questions}

This study is an attempt to answer the following research questions:

1) To what extent are creative competences of bilingual children at kindergarten available in Saudi Arabia?

2) To what extent are creative competences of monolingual children at kindergarten available in Saudi Arabia?

3) Is there any statistically significant difference at $(0.05 \geq \alpha)$ between the mean scores of monolingual kindergarten children and bilingual kindergarten children in the creative competences?

4) Is there any statistically significant difference at the level $(0.05 \geq \alpha)$ between the mean scores of the performance of bilingual male and bilingual female in the creative competences of kindergarten children scale?

5) Is there any statistically significant difference at $(0.05 \geq \alpha)$ between the mean scores of monolingual children in the age of 4 years and children in the age of 5 years in performance on the creative competence scale of the kindergarten children?

6) Is there any statistically significant difference at $(0.05 \geq \alpha)$ between the mean scores of bilingual children in the age of 4 years and children in the age of 5 years in performance on the creative competence scale of the kindergarten children?

\subsection{Research Objectives}

The objectives of the present study are:

1) Identifying the differences in the creative competences among children (monolingual and bilingual), in Saudi Arabia.

2) Pinpointing the differences between male and female bilingual children in creative competences.

3) Classifying the creative competences' differences of bilingual children, according to the age variable.

\subsection{Hypotheses of the Study}

This study will be initiated with the following hypotheses:

1) There are statistically significant differences at $(0.05 \geq \alpha)$ between the mean scores of monolingual kindergarten children and bilingual kindergarten children on Torrance scale of creative competences.

2) There are statistically significant differences at $(0.05 \geq \alpha)$ between the mean scores of bilingual kindergarten children at the age of four years and bilingual kindergarten children at the age of five years on the Torrance scale of creative competences.

3) There are statistically significant differences at $(0.05 \geq \alpha)$ between the mean scores of female monolingual children and bilingual males on the Torrance test of the capacity of creativity (originality and details).

\subsection{Definition of Terms}

Bilingualism: to know more than one language (Gutierrez-Clelln, 1999).

Creative competences: In this study, creative competence is identified by (fluency, flexibility, originality, and the 
addition or expansion).

Kindergarten child: The kindergarten child in this study is referred to the children enrolled in kindergartens in Saudi Arabia and whose ages range from (4-6).

\section{Literature Review}

\subsection{Theoretical Framework and Previous Studies}

\subsubsection{Bilingualism}

The study of bilingualism is of great importance to all members of society; hence the global openness, the accumulation of knowledge and the information revolution, and successive transitions in all aspects of economic, political, cultural, social life. In addition to that, learning languages has become a requirement, and so one of the specifications of the human being of the $21^{\text {st }}$ century is to be bilingual, trilingual or multilingual (Articles, 2000).

According to An-Najjar (2014), the tongue dualism enhances mental capacity. This is confirmed by the psychologist Janet Worker at the University of British Columbia in Canada. Worker points out that the belief that bilingual children are educationally subjected to confusion and backwardness of their monolingual colleagues is a common mistake. Worker adds that the way children grow up as bilingual is as perfectly normal as other monolingual children grow up. She also indicates that the children born in a bilingual environment can distinguish early between languages, hours after birth. Worker further states that there is no evidence that the children, who acquire a second language, have confusion or educational backwardness; rather, she and other researchers believe that the evidence actually exists to the contrary as bilingualism is considered a good thing for the child's mental ability.

Furthermore, related studies have revealed that there is a strong relationship between the creative skills and school performance, which led to the increase of research for the purpose of understanding the growth of creative competence. Scholars are trying to answer such questions as: how does creativity grow during early childhood? And why do children come to school with different creative skills? (Chang \& Burns, 2005)

On the other hand, Muller (2004) assured that language and encoding things facilitate the process of attention and control or dominate acts, thoughts and feelings. Researchers assume that a person builds in his/her mind a series of ideas before carrying out an act, as the person solves a problem through what he/she plans for, and the language contributes to facilitate it. According to Lewis (1981), a man tries to evaluate the symmetry and convergence among different objects, contrast among stimuli, and confusion or conflict among various tasks.

British and American scholars emphasize that language is isolated from creativity and that it is just a tool of knowledge, and therefore, has no effect on developing creativity (Miller, 1987). The child tries to elicit simple rules in early childhood through his/her experience, such as what to do and what he/she should use to complete the work. Accordingly how such a child reacts in an environment of two languages since things have two names, how this child behaves in this intervention in the concepts of things around him/her, and how the direction of overlapping functions responds around him/her. Some parents often wonder about the issue of teaching their children a second language in addition to their language. For example, father may be an Arab married to a woman speaking a language other than Arabic (Alawneh, 1994).

Lindholm (1980), indicated that the phenomenon of tow languages' acquisition of, bilingualism, is one of the mysterious variables and there is not sufficient knowledge about its effects on the cognitive development (Nelson \& Narsens, 1994). However, in a study on bilingual children, Bialystok (2006) found out that bilingualism gives children clear cognitive features when performing mental non-verbal tests (Bialystok, 2006; Bialystok et al., 2004).

The Italian Ricciadeli (1992) conducted a study in order to identify the relationship between bilingualism and cognitive development. The results of the study revealed that bilingual people with high skills in both languages were better than monolingual and bilingual people with low levels in both languages in cognitive development (Ricciadeli, 1992). Bilingualism is still surrounded by wrong beliefs and encircled by misunderstanding even among intellectuals, scientists and educators (Della, 2007). Some researchers like Diaz, Ferdman, Hakuta, MacNab, and Reyuolds are still not convinced with the results of the studies that showed cognitive features of the bilingual, as they believe that more researches and studies are needed (Kroll \& De Groot, 2005).

In addition, there are children in the world who acquire two languages simultaneously in the early stages of language learning as a result of their nurture in an environment dealing with more than one language. Much scientific evidence indicates that bilingual children are distinguished by cognitive features that are better than monolingual children where cognitive mechanisms, which are weak to the monolingual, can be enhanced. 
However, the researchers need to conduct many researches on the impact of bilingualism on cognitive processes (Kroll \& De Groot, 2005).

It worth mentioning that the effect of bilingual subject still occupies the attention of researchers due to the increased number of children who become bilingual in the world (Siegier \& Eisenberg, 2003). Moreover, Chomsky believes that Second Language Acquisition occurs in organization and publicity, and reflects the ways which internal cognitive mechanism controls the acquisition process regardless of the personal background of the learners or educational situation (Ellis, 1995).

Piaget believes that second language learning requires interaction, and it passes through distortion or representation and adaptation, then keeping what is being learned in the foreign mental dictionary, which is developed by the child himself. As the child has a mental dictionary of the mother tongue, he/she develops a mental dictionary for the second language. This indicates that the environmental mental images of vocabulary being built by the child vary from one child to another despite being exposed to similar materials and experiences. This is due to the fact that the degrees and levels of interaction as well as their types are different as a variety of linguistic assets developed by the child, which had a special character and experience (Kitami, 2000).

The importance of learning a foreign language in the early years has been biologically emphasized, where the child is more willing to learn languages. There is a certain important period in the left hemisphere of the brain where the language acquisition is processed. After that period, the child's ability to acquire language becomes weak, which is called the stage of brain windows. Perhaps this explains why some children can speak a foreign language, especially English, fluently in the early years. Besides, the child may be able to learn English language or a foreign language fluently till the age of ten, due to the existence of the Critical Period, a period in which the brain windows are open. The brain functions are mutually supportive after this period and so the brain gains all the knowledge, learning and experiences during this period. Long (1990) states that the critical period to acquire a foreign language means that there is a specific period in the early years of human life in which the child can acquire the ability to learn a foreign language. If they do not exploit this ability, it will be useless and so cannot be retrieved later.

The bilingual children start learning two languages as if they are learning one language. They develop a system for one of the two languages to include their components. As learning develops, they can differentiate between them and gradually deal with them as two separate languages (Vasta et al., 1999). Moreover, Abeloo (2009) stresses that the earlier the children learn the second language, the better and faster they can learn. This supports the theory of Weinberg and the critical period, or sensitive period as well, especially in language pronunciation.

In addition, Metwally (2009) points out that there are three main factors through which "Critical Period" can be interpreted and the effect of age on mastering the foreign language. These factors include biological factor, cognitive factor, and emotional factor. The biological factor indicates that the brain of the child is more flexible in the early years and thus the child can easily acquire a foreign language with perfect pronunciation. However, it becomes difficult to acquire the foreign language perfectly after a critical period.

With regard to cognitive factor, it has been realized that the child's cognitive development is rambling in a line parallel with learning language. In addition, there is a strong relation between cognitive development and language acquisition, foreign language in particular, as both influences each other. Besides, child's thinking at this stage is perceptive, which enables him/her to acquire and learn a foreign language easily.

\subsubsection{Creativity of Kindergarten Child}

Creativity can be defined as "a method or a way of thinking and performance, or performing something that is distinctive for the individual in place of the others" (Al-Baghdadi, 2001). According to Plucker and Beghtto (2004), literary creativity is the interaction between skill, process and the environment, by which the individual or the group produces a product, which is good, unique and useful, as it is distinguished within the social context. Additionally, as creativity has many different levels, it also consists of several types. According to Patrica and Johnson (2004), children express their creativity in four aspects, which include art, language, music, and acting. For example, language gives children the opportunity to express their thoughts and emotions through words, as language involves children's stories and tales as well as their creative and playing toys.

Further, in this area, El-Sawy (1995) defines creativity in language as a compilation of familiar vocabulary in a new formulation and unprecedented, as a person can use one word in an infinite number of sentences. In many cases, such sentences often seem unfamiliar, but they lead to meaning, which is the secret of creativity in its simplest and best form. 
In this regard, An-Najjar (2014), emphasizes the idea that creativity is a multifaceted phenomenon that involves a new and original production which is valuable for both the individual and the group. Creativity is also a mental activity or a process leading a production that is characterized by innovation, originality and value in the society. In addition to finding new solutions for ideas, problems and curricula, creativity is the ability to form new structures or organizations. At the same time, creativity is defined as the emergence of a new production developed by the individuals through interaction with the experiences they acquired. This leads to accomplish a new picture or develop unfamiliar uses for familiar things.

Many findings of the previous studies have revealed a list of certain activities and roles made by the teacher of the kindergarten to stimulate children's creativity in general and creativity in language, in particular. These activities and roles include: listening to children's questions and comments concerning their observations and personal attitudes, using creative questions, that is, asking questions like: "What if?" "Think of more than one use", "Think of more than one way", which is a way that can help children to think in a more creative way.

In addition, other activities include the use of "tell the story in sequence" style and the use of role playing (e.g., family events, school situations), which help children to express their own views, reactions and feelings to others (Debbie, 2006). Providing children with photographic wordless books, or using simple words representing the title of a book, allowing the children to talk about the pictures, or telling a story related to the pictures in front of them, and encouraging children to express and talk by asking questions about the sizes, forms, colors, and images (Particia \& Johnson, 2004).

\subsubsection{Components of Creative Thinking}

Creativity consists of a set of core capacities, which are mental cognitive capabilities, located mostly within the group of capacities called the capacities of mind to think, namely: fluency, flexibility, and originality. Kera (1991) indicated in her study that creativity is a capacity that can be developed in all individuals. Creativity is not connected to a certain age; rather it can be developed at all ages. This enables kindergarten children to show linguistic skills and abilities through practising different activities, provided that they are directed and employed wisely, child's language creativities can be enhanced. In order to achieve this, it is necessary to provide a convenient environment and encourage children to experiment and help them propose new ideas and experiences. This is emphasized by several studies and researches that have discussed the significance of encouraging children's creative thinking, developing it and training children on it, which is consistent with the needs and requirements of life (Vantassell \& Baska, 1994; Petocs, 2004).

The studies have also revealed that the benefit from creativity can be shown in teaching the children how to solve problems, as well as the role of creativity in raising the level of thinking efficiency of the learner. Guilford cited by Sawalha (2010) has classified the components of creative thinking under three categories according to their occurrence in the process of creativity as follows:

First: components that refer to the area of cognitive abilities, which includes the sense of problems, reorganization and renewal.

Second: components that refer to the area of productive capacities, which include fluency, originality, and flexibility. (These three aspects are the main aspects for creative thinking in science and art).

Third: components that refer to the area of appraising capacities, which include the factor of evaluation and its branches.

According to Khair (2009), creativity includes a group of basic characteristics including:

1) Fluency, which is the ability to produce many verbal and playacting ideas to a problem with a free and open ending.

2) Flexibility, which is changing the state of mind of the individual by changing the attitude.

3) Originality, which is the distinction in thinking, scarcity, and the ability to access further to the direct and conversant with the ideas and beyond.

4) Details, which is the area of experience and reaching new developments of what experiences the learner has.

5) Sensitivity to the problems, which is the individual's ability to see problems in things, habits, or systems, and viewing deficiency aspects and their deficiency.

\subsubsection{Bilingual Relationship with Creative Capabilities of Kindergarten Child}

An-Naqah and To'Aima (2002) identify language as "a set of spoken and written verbal symbols, governed by a 
particular system, which has specific functions and which is known by individuals of a particular culture. These individuals use them to express their needs and the needs of community where they live in, and through which they can communicate with each other". Language includes four skills; listening, speaking, reading, writing (Bedier \& Sadiq, 2000)

Abdel-Karim (2000) indicates that language is considered as a dimension that may reflect the capacities of the child. As the child with verbal fluency and expressions which reflect a high intelligence and advanced mental abilities can use exciting expressions that impress us. Such an expressive feature born with the child is able to grow during training on them. He recommended that it is important to stimulate the phenomenon of curiosity in children since it is an important factor in developing the power of observation, leading to further focus on child's attention and lightening his/her thought.

In addition, a creative kindergarten child is distinguished by quickly comprehending linguistic structures, imitating adults, picking up sentences, and using the functional and nonfunctional words the child has. All these are used as a new linguistic structure shown sometimes through the child's expression about himself, and about things other times. For example, kindergarten child starts using names, then acts, then letters. Next, the child offers a linguistic structure of fragmented sentences, followed by complete sentences; which helps him/her to prepare linguistic formation that contains new connections in the early stage (Ghazal, 2004).

As a consequence, language is considered as a means of linguistic creativity. Creative writing and mastering it is of extreme importance, therefore, the ancient Arab critics compared literary creativity with carriage pulled by two horses, one of which is inspiration and the other is language. (Thehni, 1988). Besides, some of the literature review revealed that there is a strong relationship between language and mental development and between mental development and creativity. As a result, the relationship is stronger between language and creativity (Owff, 2004).

\subsection{Previous Practical Studies}

\subsubsection{Bilingualism}

College Entrance Examination Board SAT test's (1992) study indicates that the grades of English language students are higher in the standardized tests in their mother tongue. Students who had spent four years or more in studying a foreign language had higher grades in the academic preparation test. It was also found that there appeared a development of self-understanding and inclusion of other cultures. Further, these children were more creative and better at solving complex problems. These results might help the present study in identifying to what extent the mother tongue is influenced by English language, and the impact of the foreign language on the cognitive development of the child. Besides, the study denies the existence of interference between the foreign language and the mother tongue.

Angelova's (1995) study proposes a model for teaching English as a Foreign Language (EFL) to children in the very early childhood stage. The study sample consisted of 184 children aged from (4-6) years. The results of the study indicated the effectiveness of the proposed model in promoting the child's ability to acquire larger and deeper knowledge of the second language and form new good language skills. The study revealed that the capacity of children to acquire knowledge and skills in other circumstances and situations improved. In addition, the cultural knowledge of the child increased because of the kinetic games of learning.

Virginia (1996) conducted a study to examine two cases of children in an attempt to shed light on the significance of identifying the cultural faculty in the first language in a sample of kindergarten children who speak only Spanish as their first language or who speak Spanish with a little of English. In the first case study, the children were speaking Spanish only and they showed no linguistic talent or linguistic intelligence. However, the other children were speaking Spanish and had low efficiency in English having linguistic talent. Results of the study indicated that there is a correlation between learning two languages in children kindergarten and cognitive development and faculty in the early childhood.

Kwan (1998) implemented a study to investigate the relationship between stereotype activities, the experience of social activities of children, and language development. The study showed the cognitive, physical, and household activities and social integration of children. Kwan compared two groups; the first group was of high progress in language development, whereas the second group was of low progress in language development. Results of the study indicate that the group of high progress in language development has an increase in the cognitive activities and muscle activities, as well as verbal interaction with others.

Bialystok and Shapero (2005) examined the ability of bilingual and monolingual children at the age of six years in identifying alternative form of inverted image. Results indicated superiority of bilingual children in the 
interpretation of the meaning of images.

Wouter (2007) directed a study to detect the lexical ability in reading in a sample of young Dutch children. This sample was divided into two groups: a group of children who speak English as a second language, and another control group speaking mother tongue only. The researcher has conducted three experiments. The results showed that the children who speak English as a second language have a higher visual perception of the word than their peers who speak only mother tongue.

Youb (2008) applied a study to compare the effectiveness of two different methods to learn English as a second language for kindergarten children. The first method was a combination of both oral and written education. The second approach was verbal learning, that is, to learn it verbally only. In addition, the study investigated the impact of these methods on the development of oral language skills. The results of the study indicated that the children who had studied in verbal and in writing fields became better in the oral and cognitive development.

Metwally (2009) implemented a quasi-experimental study that thirty of Al-Riyadh kindergarten children participated in. The objective of the study was to explore the effect of child's learning in English science education on cognitive development. The sample was divided into two groups: the experimental group $(\mathrm{n}=15)$ children from Al-Awqaf kindergarten children, and a control group $(\mathrm{n}=15)$ children from Al-Awa'el local kindergarten children at Sebarbai village in Tanta Center. The researcher administered the cognitive development scale that had been distributed to the two groups before the experiment. The proposed approach of the piloted group was presented for eight weeks. After experimentation, a posttest was administered to both groups (cognitive development scale). Findings of the statistical analysis indicated that there were statistically significant differences at 0.05 between the mean scores of the experimental group and the control group on the pretest- posttest in favour of the experimental group.

\subsubsection{Creativity of Kindergarten Children}

Al-Ameri's (2008) study aimed at identifying the effect of role-playing on developing the capabilities of innovative thinking of Riyadh children. The researcher used the experimental design related to the control and experimental groups. The study sample consisted of 30 boys and girls divided into two experimental and control groups. Each group consisted of 15 boys and girls. The study concluded that the experimental group achieved a significant increase in all capacities of creative thinking and that there was a statistical significant difference at $(\alpha=0.05)$.

Al-Kilabi et al. (2013) in their study examined the impact of playing drama in the development of creative thinking of children aged 4-5 years. The researchers used the experimental method, the design of equal groups, which is a system for testing or comparing two or more groups, as it is convenient to the nature of the research problem to be solved. Moreover, the population of the research was determined by Al-Amal kindergarten children aged 4-5 years in Babel Governorate consisting of 80 children in the academic year (2012-2013). The study concluded that the playing drama had a positive effect in the development of creative thinking among children aged (4-5) years between the two groups of control and experimental in favor of the experimental group.

\subsubsection{Comments on Previous Studies}

It has been realized that the grades of foreign language students were higher in the achievement tests in the first language. Further, children were more creative and better at solving complex problems as indicated in a study conducted by College Entrance Examination Board (1992). The study of Angelova (1995) showed an improvement in the capacities of bilingual children to acquire knowledge and skills under circumstances and in other situations. The study also showed an increase in the cultural knowledge of the child.

Furthermore, according to Virginia (1996), there appeared a correlation between learning two languages in kindergartens and cognitive development and faculty in the early childhood. Findings of some studies indicated that there was an effect of bilingualism on the academic achievement as shown by Armstrong \& Rogers (1997), who emphasized the superiority of bilingual students in the achievement tests in mathematics, language and verbal interaction with others. Additionally, in a study conducted by Bialystok and Shapero (2005), findings revealed that bilingual children improved better in the interpretation of symbols, images and visual perception.

In addition, there were other studies such as the study of Youb (2008) and the study of Metwally (2009) which showed that the progress of bilingual children was better in the oral language and cognitive development. However, it has been realized that previous studies are different from present study in the objectives and the results, where this study is consistent with the previous studies in sampling and the independent variable. 


\section{Methodology}

\subsection{Procedures}

In this study, the researcher used the experimental method as it is convenient to the nature of the study.

\subsection{Sample}

The sample in this study was randomly chosen. The sample was divided into two groups: the bilingual group (n $=40)$, and the control monolingual group $(\mathrm{n}=40)$.

\subsection{Instruments}

The study used the scale of Torrance creative capacity in order to identify the creative abilities of children.

\subsection{Reliability and Validity of Creative Capacity Scale}

Reliability was ensured by re-testing the stability of the application on the sample and then re-applying it (15) days later. The correlation factor between the two applications was $(0.87)$, which was a strong reliability factor. However, validity of the scale was verified in a consistent manner through applying the internal variable on an exploratory sample from outside the research sample that consisted (30) boys and girls. Pearson correlation coefficient was calculated between the scores of each variable of the scale and the total score of the scale.

\section{Findings and Discussion}

Findings of the present study have been achieved through the application of Torrance measure of creative thinking on the research sample.

\subsection{Findings of Hypothesis \# 1}

There are statistically significant differences at $(0.05 \geq \alpha)$ between the mean scores of monolingual and bilingual kindergarten children on Torrance measure of creative capabilities.

To answer Hypothesis \# 1, T-test was used for the independent groups. Results are shown in Table 1.

Table 1. T Value for the significance of differences between mean scores of single language \& bilingual kindergarten children on torrance measure of creative capabilities

\begin{tabular}{lccccc}
\hline & \multicolumn{4}{c}{ Kindergarten } & \\
\cline { 2 - 4 } Creative & \multicolumn{2}{c}{ Monolingual $(\mathrm{N}=40)$} & \multicolumn{2}{c}{ Bilingual (N=40) } & \multirow{2}{*}{ T Significance } \\
\cline { 2 - 4 } & Mean & $\begin{array}{c}\text { Standard } \\
\text { deviation }\end{array}$ & Mean & $\begin{array}{c}\text { Standard } \\
\text { deviation }\end{array}$ & \\
\hline Fluency & 14.63 & 3.90 & 13.70 & 3.93 & 1.05 \\
Flexibility & 10.93 & 4.23 & 9.30 & 3.05 & $1.96^{*}$ \\
Originality & 20.58 & 9.64 & 16.28 & 8.00 & $2.17^{* *}$ \\
Details & 14.28 & 8.86 & 10.33 & 5.67 & $2.37^{* *}$ \\
Total score & 60.40 & 24.56 & 49.60 & 18.46 & $2.22^{* *}$ \\
\hline
\end{tabular}

* Sig. at $(\alpha=0.05), * *$ Sig at $(\alpha=0.01)$.

Table 1 shows that there are statistically significant differences at $(\alpha=0.05)$ between the mean scores of monolingual kindergarten children and the mean scores of bilingual kindergarten children in flexibility in favor of monolingual children. In addition, results show that there are statistically significant differences at $(\alpha=0.01)$ between the mean scores of monolingual children and the mean scores of bilingual children in both: authenticity and details in favor of monolingual children. Also, it is obvious that there is no statistically significant difference between the mean scores of monolingual children and the mean scores of bilingual children.

With regard to the presence of statistically significant differences at $(\alpha=0.01)$ between the mean scores of monolingual children and the mean scores of bilingual children: flexibility, originality, details and the total score were in favor of the monolingual children. As a result, the first hypothesis was rejected and the zero hypothesis was accepted.

Results of the present study are different from the results of Bialystok's (2005) study and Bialystok and Shapero (2005) during their study of bilingual children. They reported that bilingualism gives children clear cognitive 
features when performing mental non-verbal tests.

According to the result, there is no statistically significant difference between the mean scores of monolingual children and the mean scores of bilingual children in fluency. On other words the performance of bilingual children is similar to the performance of monolingual children in a variety of tasks. These tasks include drawing a line through an upward series from scattered numbers on a sheet, which is due to the activities that exist depending on the use of "telling a story sequentially" style, the use of role playing (family issues, school situations), which help children to express their own views to others and express emotions and feelings with monolingual children and bilingual children (Flower, 1997; Debbie, 2006). The tasks also involve providing children with picture books without words, or with words representing a simple book title through which the children are allowed to talk about the pictures, or tell a story about the pictures in front of them. Further, they include encouraging children to express and talk through asking questions about the sizes, forms, colors, photos of monolingual and bilingual children (Particia \& Johnson, 2004).

Furthermore, kindergarten children are generally creative regardless of monolingualism or bilingualism. They are characterized by understanding linguistic structures rapidly, imitating adults, learning sentences fast, and using meaningful words, and yet using meaningless words as a new linguistic structure. Ghazal (2004) pointed out that kindergarten children start using names, verbs, letters, and presenting a language structure of broken sentences, and then they use complete sentences, which can help them in an early stage to prepare a linguistic formation of new connections.

\subsection{Findings of Hypothesis \# 2}

There is no statistically significant difference at $(0.05 \geq \alpha)$ between the mean scores of bilingual kindergarten children at the age of four years and bilingual kindergarten children at the age of five years on the Torrance measurement of creative abilities. Results are shown in Table 2.

Table 2. T value of the significance of differences between the mean scores of four \& five year bilingual kindergarten children on the torrance measurement of creative abilities

\begin{tabular}{lccccc}
\hline & \multicolumn{4}{c}{ Kindergarten bilingual } \\
\cline { 2 - 4 } Creative & \multicolumn{2}{c}{4 years old $(\mathrm{N}=20)$} & \multicolumn{2}{c}{5 years old $(\mathrm{N}=20)$} & \\
\cline { 2 - 4 } & Means & $\begin{array}{c}\text { Standard } \\
\text { Deviation }\end{array}$ & Means & $\begin{array}{c}\text { Standard } \\
\text { Deviation }\end{array}$ & \\
\hline Fluency & 13.1 & 4.412 & 14.10 & 3.291 & 422 \\
Flexibility & 8.95 & 2.874 & 9.55 & 3.268 & 541 \\
Originality & 16.95 & 7.983 & 14.80 & 6.330 & 351 \\
Details & 10.60 & 6.142 & 10.00 & 5.282 & 742 \\
Total score & 49.60 & 19.898 & 48.45 & 15.942 & 841 \\
\hline
\end{tabular}

* Sig. at $(\alpha=0.05),{ }^{*}$ Sig at $(\alpha=0.01)$.

Table 2 above indicates that there is no statistically significant difference between mean scores of bilingual kindergarten children at the age of four years and bilingual kindergarten children at the age of five years in terms of fluency, flexibility, originality and detail. Therefore, the present hypothesis was rejected and so accepting the zero hypothesis.

The result is in consistent with the results of some previous studies. For example, Torrance conducted studies that tackled the development of children's creative abilities during a long age phase. He pointed out that child creative development goes through periods of prosperity where creative ability appears to be in its best. Then it approaches through periods of decline, crumpling or latency where creative ability weakens or does not appear at its best.

Moreover, Torrance indicated that among the most important latency periods is the period of age five, the age when the children, the participants of the sample, enter the school. It is the period through which they drew their results from and attributed that to the enrollment of children in kindergartens. This stage has been witnessing some education and starting receiving the skills of reading, writing and math, where the extra learning processes of these skills lead to develop the left hemisphere of the brain and impede the right hemisphere. This part is 
supposed to be responsible for the special activities of creativity and imagination. Besides, Torrance, assured that some creative abilities approach organized advancement, whereas some other abilities do not develop at certain age stages and do not improve as much as some other abilities.

\subsection{Findings of Hypothesis \#3}

There are no statistically significant differences at $(0.05 \geq \alpha)$ between the mean scores of female and male monolingual and bilingual children on Torrance measurement of creative capacity (i.e., originality and details). In order to answer the question of the hypothesis, a T-test was applied for independent groups. Results are shown in Table 3.

Table 3. $\mathrm{T}$ value for the significance of differences between mean scores of kindergarten monolingual and bilingual children on originality and details

\begin{tabular}{lccccc}
\hline \multirow{2}{*}{$\begin{array}{l}\text { Creative } \\
\text { Capacity }\end{array}$} & \multicolumn{3}{c}{ Male $(\mathrm{N}=40)$} & \multirow{2}{*}{ Fender } & \multirow{2}{*}{ T Significance } \\
\cline { 2 - 4 } & Mean & $\begin{array}{c}\text { Standard } \\
\text { deviation }\end{array}$ & Mean & $\begin{array}{c}\text { Standard } \\
\text { deviation }\end{array}$ & \\
\cline { 2 - 4 } Fluency & 13.53 & 3.20 & 14.80 & 4.48 & 1.46 \\
Flexibility & 9.40 & 3.52 & 10.83 & 3.88 & 1.72 \\
Originality & 16.03 & 7.59 & 20.83 & 9.85 & $2.44^{* *}$ \\
Details & 9.98 & 6.87 & 14.63 & 7.77 & $2.83^{* *}$ \\
Total Score & 48.92 & 19.52 & 61.07 & 23.38 & $2.52^{* *}$ \\
\hline
\end{tabular}

* Sig. at $(\alpha=0.05), * *$ Sig. $(\alpha=0.01)$.

Table 3 above illustrates there are statistically significant differences at $(\alpha=0.01)$ between kindergarten monolingual and bilingual children in both originality and details in favor of females. Moreover, results show statistically significant differences between monolingual and bilingual children in both fluency and flexibility.

Obviously, the above table indicates that there is statistically significant difference between the mean scores of male and female average scores in originality and details of male and female in favor of females. This conclusion is relatively in agreement with the results of previous studies. For example, Isa (1988) whose study's results showed that females are superior to males in originality. These results were interpreted in the light of female situations in Arab societies by virtue of their social nurture. Further, girls are subjected to cultural authorization of certain kind on a particular type of activity since they were born. This might reach the degree of pressure in the direction of creating motivation, personal and cognitive attributes female in a certain way, which eventually leads to making a creative behavior that does not necessarily agree with the creative behavior resulting from males, who have also their distinctive features saturated in what the society is concerned to instill into them and train them on it accordingly.

Furthermore, the results of this study are in agreement with the results of Ramzi's (1991) study, which dealt with gender differences in mental abilities. Ramzi (1991) found out that the early stages of the age witness superiority of females to males in this regard. However, by growing up, the superiority becomes less; even though one gets to the end of adolescence and the beginning of maturity, males will become superior to females in the general level of intelligence. A plethora of research has discussed the superiority of females to males in the pre-school stage and in the first years of study in most aspects of verbal performance. It has been noticed that females start pronunciation earlier, use longer sentences and talk more of greater fluency as much in an early age stage. In spite of this superiority, such differences start to disappear in the stage of entering school where almost both genders are equal in these capacities.

However, the results of this study are different from the results of some studies, one of which is Issa's (1988), where males and females were compared and contrasted in terms of creative abilities. The results of the study revealed that there are significant differences between males and females in these capacities in favor of males. The study is also different from the overall results of other international studies, which showed that creative females are fewer, in number, than the creative males. These results were interpreted to cultural factors that make female exposed to social challenges in the direction of appeasement and continuation on the one hand, and the 
field of creativity.

To add more, the results of this study are different from the results of Ramzi's study (1991), whose results revealed no significant differences between males and females in the pre-school stage in creative abilities. It seems to be that societal pressures imposed by society on girls do not let their effects appear at such an early age in children's lives. In addition, the results of the present study are contrary to most of the previous studies that have emphasized the superiority of bilingual children in the capacities of cognitive development, and the acquisition of knowledge (Angelova, 1995; Virginia, 1996; Bialystok \& Shapero, 2005; Wouter, 2007; Youb, 2008; Metwally, 2009).

To sum up, the difference of the results of this study from most of the previous studies is attributed to the cultural and economic differences between the two samples, which were difficult to adjust such extraneous variables to the search result. One can find out that most parents of monolingual children hold university degree and qualifications. On the contrary, the sample of bilingual children where the parents are from different educational levels, could affect children's creative capacities and eventually affecting the search results.

In addition, the result of the present study can be attributed to the focus on the foreign language at home and at school in the sample of bilingual children. Bilingual children were not also keen on bilingual when providing them with gifts for their sense of participation in the scale, because they have toys even better. Besides, the bilingual children were not disciplined during the application of the scale, which may be due to the method of parental treatment and excessive pampering at home and kindergarten.

\section{Recommendations}

In light of the findings of this study, the researcher recommends the need of:

1) Resolving the controversy over the issue concerning when children can start to learn a foreign language.

2) Conducting studies to ascertain the extent of influencing Arabic language when children learn a foreign language.

3) Implementing studies on the negative and positive effects of learning foreign language on children in kindergarten.

4) Managing studies concerning the impact of foreign language learning on the creative capacities of other samples.

5) Investigating the effect of the economic and cultural levels of the parents on the creative capacities of children.

\section{References}

Abdel-Karim, E. (2000). Developing Language Skills of the Child. Cairo: The World of Books.

Abeloo, Ch. (2009). Age and the Critical Period Hypothesis. ELT Journal Advance Access originally published online on ELT Journal 2009, 63(2).

Abu Jado, S. (2004). Social Nurture. Amman: Darul-Maseerah for Printing and Publishing.

Al-Ameri, A. (2008). The Effect of Role Playing on the Capacities of Innovative Thinking among Riyadh Children. College of Elementary Education, 53.

Alawneh, Sh. (1994). Psychology of Human Growth, Childhood. Amman: Darul-Forqan for Publishing and Press.

Al-Baghdadi, M. (2001). Creative Activities for Children. Cairo: Arab Thought Press.

Al-Kilabi, A., \& Tayeh, T. (2013). The Effect of Role Playing on Developing Creative Thinking among Children aged 4-5 years. Journal of Physical Education Science, 7(2).

Al-Sawi, M. (1995). Creativity in the Writings of Zaki Najeeb Mahfouz: An Analytical Study. The Future of the Arab Education Journal, 1(1).

Angelova, T. (1995). A Model of Early Childhood Foreign Language Education through Playing Motoric Games. ERIC ED. Articles, F; Reading and Foreign Language Learning. Annals of Dyslexia Part Iv, 2000.

An-Najjar, M. (2014). The Duplication of the Tongue Enhances Mental Capacity. Qatar: Aljazeera press.

An-Naqa, M., \& To'eima, A. (2009). Arabic Language and Global Understanding. Amman: Darul-Maseerah.

Baska, A. (1994). Comprehensive Curriculum for Gifted Learners. USA: Botom, Ellyn And Bacon Press. 
Bialystok, E. (2006). The Effect of Bilingualism and Computer Videogame Experience on the Simon Task. Canadian Journal of Experimental Psychology, 60(1), 68-79. http://dx.doi.org/10.1037/cjep2006008

Bialystok, E., \& Shapero, D. (2005). Ambiguous Benefits: The effect of Bilingualism on Reversing Ambiguous Figures. Developmental Science, 8(6), 595-604. http://dx.doi.org/10.1111/j.1467-7687.2005.00451.x

Bialystok, E., Craik, F., Klein, R., \& Viswanathan, M. (2004). Bilingualism, Aging, and Cognitive Control: Evidence from the Simon Task. Psychology and Aging, 19. http://dx.doi.org/10.1037/cjep2006008

Chang, F., \& Burns, B. (2005). Attention in preschoolers: Associations with effortful control and motivation. Child Development Journal, 76.

College Entrance Examination Board. (1992). College Board Seniors-Profile of SAT and Achievement Test Takers. National Report. New York: College Entrance Examination Board, ED223708.

Debbie, W. (2006). Encouraging Creativity in Children. Retrieved from http://www.earlychildhood.com

Della S. (2007). Tall Table About The Mind and Brain. U.K.: Oxford University Press.

Ellis, R. (1995). The Study of Second Language Acquisition. U.K.: Oxford University Press.

Flower, L. (1997). Encouraging Creativity in Children, Cooperative Extension Service. Ohio: State University Press.

Ghazal, A. (2004). An Exploratory Study of Linguistic Creativity for a Sample of Linguistically Creative Children at the Age of Five and the contribution to Their Development Using Enriching Program. Second Scientific Conference, Bani Sweif University 2004, Faculty of Education.

Gutierrez-Clellen, V. (1999). Language Choice in Intervention with Bilingual Children. American Journal of speech -language pathology, 8, 291-302. http://dx.doi.org/10.1044/1058-0360.0804.291

Issa, A. (2014). The Impact of Role Playing Program on Developing Creative Thinking among Children Aged 4-5 Years. Physical Education Journal, 7(2).

Kera, B. (1993). Teaching Language Arts: Expanding Thinking. Developmental Science, 4.

Kitami, J. (2000). The Child's Cognitive and Linguistic Development. Jordan: Al-Ahleyya for Publishing and Distribution.

Kroll, J., \& De Groot, A. (2005). Handbook of Bilingualism. UK: Oxford University Press.

Kwan, C. (1998). Typical Child Behaviours in Singapore. Day Care Centers and their Relationship with Language Development. ERIC ED 421245.

Lewis, J. (1981). Human Being: That Unique Being. Baghdad: Darul-Horreyah Press.

Lindholm K. (1980). Bilingual children: Some Interpretations of Cognitive and Linguistic Development. In K. Nelson (Ed.), Children's language, 2. New York: Gardner Press.

Long, M. (1990). Maturational Constraints on Language Development. Studies in Second Language Acquisition, 12, 251-285. http://dx.doi.org/10.1017/S0272263100009165

Metwally, M. (2009). Child's Learning of Science Education in English and Its Impact on Cognitive Development in Light of Critical Age Theory. (Unpublished PhD thesis, Faculty of Education, Tanta University, Egypt).

Miller, S. (1987). Psychology of Playing. Kuwait: The World of Knowledge.

Muller, U., Zelazo, P., Hood, S., Leon, T., \& Rohrer, L. (2004). Interference Control in a New Rule Use Task: Age-Related Changes, Labeling, and Attention. Child Development Journal, 75(5).

Nelson, T., \& Narens, L. (1994). Why Investigating Metacognition. In J. Metcalfe, \& A. Shimamura (Eds.), Metacognition: Knowing about knowing. New York: Plenum, Cambridge Press.

Owff, A. (2000). Developing Creativity in the Different Stages of Childhood. Cairo: Egyptian Anglo Library.

Particia A., \& Johnson, D. (2004). Cooperative Extension. U.S.A.: Colorado State University Press.

Petocs, P. (2004). Learning Domains and the Process of Creativity. Journal of Creative Behavior, 31(2).

Plucker, J., \& Beghtto, R. (2004). Why isn't Creativity More Important to Educational Psychologist. Journal of Creative Behavior, 39(2).

Ramzi, J. (1991). A Proposal for Developing Creative Competences in the Field of Story to the Children of 
Kindergarten Stage (Unpublished master thesis, Faculty of Education in Damietta, Mansoura University. Egypt).

Ricciadeli, L. (1992). Bilingualism and Cognitive Development in Relation to Threshold Theory. Journal of Psycholinguistics Research, 21.

Sawalha, A. (2010). Psychology of Playing. Amman: Darul-Maseerah for Publishing and Distribution.

Siegier, R., Deloache, J., \& Eisenberg, N. (2003). How Children Develop? USA: Worth Publisher MIT Press.

Thehni, M. (1987). Literature Appreciation. Cairo : Darul-MaAref.

Vantassel, J., \& Baska, A. (1994). Comprehensive Curriculum for Gifted Learners. USA: Botom, Ellyn and Bacon.

Vasta, R., Haith, M., \& Miller, S. (1999). Child psychology: the Modern science. NewYork: John Wiely \& Sons.

Virginia, G. (1996). Identifying Gifted Bilingual Hispanic Kindergarten with Alternative Sociocultural Dual Language Assessment. Paper presented at the annual meeting of the American Educational Research Association, New York, ERIC, ED 395457.

Wouter, D. (2007). Visual word recognition by bilinguals in a sentence context: Evidence for nonselective lexical access. Journal of Experimental Psychology: Learning, Memory, and Cognition, 33(4).

Youb, K. (2008). The Effects of Integrated Language-Based Instruction in Elementary ESL Learning. Modern Language Journal, 92(3).

\section{Copyrights}

Copyright for this article is retained by the author(s), with first publication rights granted to the journal.

This is an open-access article distributed under the terms and conditions of the Creative Commons Attribution license (http://creativecommons.org/licenses/by/4.0/). 